\title{
Editorial to the special issue on the 2015 TOUGH Symposium
}

\author{
Christine Doughty $^{1}$ - George J. Moridis ${ }^{1}$
}

Published online: 21 May 2018

(C) This is a U.S. Government work and not under copyright protection in the US; foreign copyright protection may apply 2018

This Special Issue of Transport in Porous Media features selected papers from the 2015 TOUGH Symposium, which took place on September 28-30, 2015, in Berkeley, California, USA. Such symposia are held every 3 years and are a forum where users of the TOUGH family of numerical simulators meet for an open exchange on the code applications and recent enhancements. The TOUGH codes (TOUGH is an acronym for Transport of Unsaturated Groundwater and Heat) were originally developed in the early 1980s for geothermal reservoir simulation by a team of researchers at the Lawrence Berkeley National Laboratory (LBNL) headed by Karsten Pruess (see http://esd.lbl.gov/TOUGH). The TOUGH codes have a modular structure in which different fluid components can be incorporated into the code by means of a replaceable equation of state (EOS) package. Since its first release, a variety of important EOS modules have been developed, enabling the modeling of volatile organic compounds, decay chains of multiple radionuclides, gas hydrates, tight and shale gas behavior, enhanced oil recovery, and supercritical water and $\mathrm{CO}_{2}$. Derivatives and descendants of the basic TOUGH code include coupled multi-phase flow and reactive chemical transport; coupled thermo-hydrologic-mechanical processes; inverse modeling for parameter estimation, sensitivity analysis, and uncertainty quantification; and parallelization for multi-core PCs, workstation clusters, and supercomputers. The TOUGH codes have been applied to a large variety of problems, including geothermal and petroleum reservoir engineering, nuclear waste and $\mathrm{CO}_{2}$ geologic sequestration, subsurface environmental remediation, methane gas hydrate production, compressed air energy storage, and many other energy and environmental applications. The international TOUGH user community currently numbers almost 400 organizations (research laboratories, government agencies, private companies, universities, etc.) in over 60 countries.

During the 2015 TOUGH Symposium, approximately 100 attendees from 19 countries gathered over 3 days to present more than 80 papers in oral and poster formats about their

Christine Doughty

cadoughty@lbl.gov

1 Energy Geosciences Division, Lawrence Berkeley National Laboratory, Berkeley, California, USA 
applications and enhancements related to the TOUGH codes. The philosophy behind the LBNL's development and distribution of the TOUGH codes is to make new developments available to the community at low cost, either as executable or source code, or both. Access to source code means that users can customize the code for their specific purposes. When these researchers allow the LBNL to incorporate their improvements and distribute the new capabilities, even more people benefit from the development work. So while the TOUGH codes are not formally a community code, many of the developments find their way back to the LBNL and public distribution.

The papers at the symposium were organized into the following sessions:

Geologic carbon dioxide storage

Geothermal reservoir engineering

Nuclear energy and waste

Hydrocarbon recovery and reservoir processes

Environmental engineering and vadose zone

Coupled fluid flow and geomechanics

Reactive transport

Numerical methods, including grid generation, and parallel computing

Optimization, parameter estimation, data-worth analysis.

As for past TOUGH symposia, some of the authors who presented papers across a range of subject areas at the TOUGH Symposium 2015 were invited to submit full journal papers for inclusion in peer-reviewed journal special issues. This Special Issue of Transport in Porous Media includes seven papers that cover a wide spectrum of subjects. Environmental engineering papers examine water flow in a layered snowpack, and radon transport at the soil-building foundation interface. One hydrocarbon recovery paper couples gas flow and geomechanics to solve problems in underground natural gas storage, while another uses the dusty gas model to study methane diffusion and adsorption in shale rocks. Optimization papers investigate means for fast inversion for large models of deep aquifer systems, and the importance of including anisotropy in the analysis of laboratory pressure-pulse-decay experiments. Finally, a nuclear energy and waste paper models the pressure and deformation response to gas injection tests. We hope that this Special Issue will be a valuable addition to the library of engineers, scientists, and technology specialists involved in various aspects of system behavior during flow and transport through complex geologic media, and especially to current and future users of the TOUGH codes.

In concluding, we would like to express our thanks and appreciation to the many authors, session organizers, and chairs that made the symposium an unequivocal success, and our gratitude to the various reviewers for their outstanding efforts in evaluating the papers and making the publication of this Special Issue possible. 